\title{
Socio-Economic Factors of Empowerment in Developing Countries
}

\section{Rabnawaz Khan ${ }^{1}$ \\ Jin Xinxin ${ }^{2 \star}$ \\ Yusheng Kong ${ }^{3}$ \\ Emmanuel Yamoah Cobbold}

${ }^{1,4}$ School of Finance and Economics, Jiangsu University, Jiangsu, Zhenjiang, People's Republic of China.

${ }^{2}$ School of Literature and Language, Jiangsu University, Zhenjiang, Jiangsu, Zhenjiang, People's Republic of China.

Emaili1048186766@qq.com

${ }^{3}$ School of Finance and Economics, Jiangsu University, Zhenjiang, People's Republic of China.

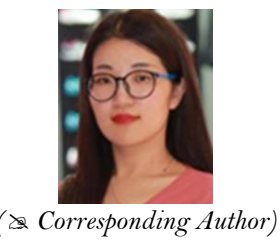

( Corresponding Author)

\section{Abstract}

The study is carried to identify the main socio economic cultural and political view determinants of women empowerment in the developing countries. The highest determination of the study is to analyze and identify the variables through which the process of women empowerment can be measured. This study is based on secondary data and reported to analyze the empowerment factor of women in 124 developing countries, the data was ordinal in nature and randomly selected from the population. The main investigation of this research study to analyzed the relationship of women fertility, socio-economic and political factor on the women empowerment. After conducting a cross sectional study for the most recent period, the findings of study show that the main deterrents towards women disempowerment are attributed as high fertility rates, high maternal mortality, gender inequality, lack of female's access towards education, health and economic opportunities, lack of leadership and decision making qualities. It is found that a patriarchal culture is equally responsible for women in sufferings and disempowerment. However, democracy and democratic culture can contribute well in upgrading the process of women empowerment in developing countries.

Keywords: Democracy of women, Socio-economic factors of Women empowerment impact, Health effects, Education, Political impact. JEL Classification: F43; F63; $115 ; 125$.

Citation | Rabnawaz Khan; Jin Xinxin; Yusheng Kong; Emmanuel Yamoah Cobbold (2020). Socio-Economic Factors of Empowerment in Developing Countries. Asian Journal of Economics and Empirical Research, 7(2): 159-170.

History:

Received: 10 April 2020

Received: 10 April 2020

Revised: 13 May 2020

Accepted: 16 June 2020

Published: 28 July 2020

Licensed: This work is licensed under a Creative Commons Attribution 3.0 License (c)) E

Publisher: Asian Online Journal Publishing Group
Acknowledgement: All authors contributed to the conception and design of the study.

Funding: National Natural Science Foundation of China No: 71371087. I am also grateful my beloved comrade Jin Xinxin who helpful in each stage and stipulating me many times during my graduate school career. As a role model, mentor, and kindhearted, I never ever deny that thought or ideas who was really appreciating for me, but I also realized that my unknown anticipation is never ever to hold her benevolence with factual thought.

Competing Interests: The authors declare that they have no conflict of interests.

Transparency: The authors confirm that the manuscript is an honest, accurate, and transparent account of the study was reported; that no vital features of the study have been omitted; and that any discrepancies from the study as planned have been explained.

Ethical: This study follows all ethical practices during writing.

\section{Contents}

1. Introduction.

2. Literature Review

4. Data Analysis .

5. Results

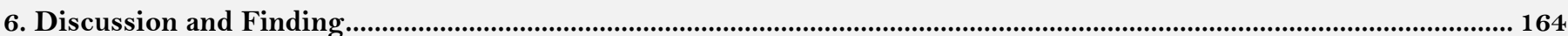

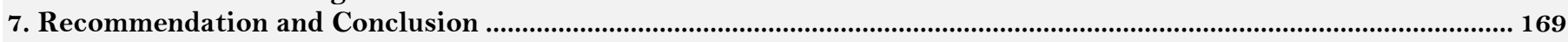

References... 


\section{Contribution of this paper to the literature}

This paper is indicating the women empowerment by socio-economic factor, fertility and political factor in the 142 developing countries. The prior research study concluded that the empowerment of women which positively affect the development and growth process of a country.

\section{Introduction}

The question of how women can be made more empowered has assumed increasingly important dimensions in the field of planning and development. Empowerment of women are essentially the process of uplifting economic, social, and political status of women in the society. This study argues that women empowerment needs a multidimensional strategy encompassing economic, social, cultural, and political impact reform.

For all this it is vital that women should have equal opportunities to participate in socio-economic and political frameworks. In other words, for the process of female empowerment it is necessary that women should be able to act freely, and acquire power to exercise their rights and potentials. Thus, women empowerment can be defined as a process through which women get an equal and equitable status and position in a society. Women empowerment has been defined as women access to get education, healthy economic and political access (Sweeney, Wilson, \& Brown, 2019). Women are regarded as a best form of human capital and are regarded as important assets for a society and indispensable for the process of development (Goldstein et al., 2019). Research indicates that investments in women's employment, health, and education, are correlated with a range of positive outcomes. In this respect Gender development studies in many countries reveal that for the process of growth and progress women should be able to enjoy equal rights in a society. But it is observed that socio-economic position of women in developing societies negatively affect their participation. Traditions, cultures, laws, illiteracy, public unawareness, high fertility rates all contribute to the powerlessness of women in underdeveloped economies (Liu, Yu, Bai, \& Chen, 2020).

Economic empowerment is one of the most powerful routes for women to achieve their highest potentials. Numerous researches reveal that in developing countries, education and employment are the two strong social factors which can increase the process of women empowerment. Women education, awareness and knowledge are critical to their complete success. The importance of female education he said that educated women can create educated children and educated mothers educate family which results in an educated population of a nation which builds a strong nation (Montanari \& Bergh, 2019).

Women education is a powerful tool to modify their position and status in a society. Education is considered as a milestone for women empowerment because it gives them the opportunity to respond to the challenges, to confront their traditional role and to change their lives. Education is just as important and necessary for women access to jobs, mobility, political participation, good health, and legal systems (Kim, 2018; Malapit et al., 2019).

Women political participation is also an important tool and element in the process of empowerment. To empower women. It is essential that they should equally participate in the decision making process. It is vital because it will enhance their status in a society (Kumar, 2020). Nonetheless, in developing societies there are a number of such structural, social, cultural, economic and institutional factors which offer constraints towards women participation in politics.

Geneva Based Gender Gap Index 2014(UNDP) has depicted the situation of gender inequalities to assess the process of female empowerment in many countries for example it reveals from its report that India was ranked 134th for economic opportunity and participation, 126th for education, an impressive 15th for female political empowerment but 142nd, the second last, for health and survival. Pakistan ranked 141st out of 142 countries in terms of economic opportunity and political participation for women, 132nd for access to education, 119 th in health and survival and 85 th for political empowerment.

Women empowerment is a multidimensional concept. To measure and monitor empowerment processes and outcomes, several frameworks and indices have been developed internationally like Gender related development index GDI, Gender gap index GGI, Gender empowerment index GEM, and Gender inequality index GII. However, to synthesize and measure the process it is difficult to select any measure as an index of women empowerment, which can truly determine the effects of various socio-economic and political factors on women empowerment. However, in the present analysis cross sectional study is done to measure the process, taking fertility rate as an indicator of women empowerment.

The present study is carried out with following specific objectives:

1. To identify the Democracy, Health, economically view, Education and Politics factors that affect women empowerment across the selected countries.

2. To critically assess the reasons behind the denial of women empowerment.

3. To suggest practical steps for the improvement of women empowerment in a society.

\section{Literature Review}

The following dimensions which should be considered while measuring the process of empowerment i.e. legal, political, and economic and socio-cultural dimensions. Global health institute survey 2014 also indicates that female empowerment has multiple, interrelated and interdependent dimensions i.e. economic, social, cultural and political impact. That socio economic and political empowerment of women is an important element and is necessary for reducing their sufferings and for their equal participation in society. Fisch et al. (2018) That there are a number of factors through which the process of women empowerment can be increased i.e. increasing their rights, resources, dignity, choices and opportunities. Gambia found that there exists a strong positive relation between various socio economic and political aspects of women participation and the level of women empowerment. Jahromi et al. (2019) Hence improvements in women's well-being in terms of better health, nutrition, increased income, education, reduced violence, longer life span etc. are seen as prerequisites for women empowerment. Female educational attainment, while studied female educational attainment, enrollment ratio, and "Index of femaleness" in 
education.Vermeulen et al. (2018) A research paper, concluded that to increase the process of women empowerment in sub Saharan African and Asian countries, there should be availability of increased health services for poor women controlling birth rates, controlling maternal mortality ratios, the process of women empowerment can be promoted (Matro, Martin, Wolf, Shah, \& Mahadevan, 2018; Riahi, Mohammadi, Rohani, \& Bidkhori, 2018).

The prior research concluded that in most of the countries globally there exists a positive and direct relation between women empowerment and their economic participation, which also positively affect the development and growth process of a country. Research in India, on women empowerment concluded that women economic participation affects their power of decision making, their freedom of movement and control over resources. He used certain demographic variables in his study and found that the role of education is crucial for female economic participation (Teitelman, Kim, Waas, DeSenna, \& Duncan, 2018). He said that literacy, improved skills and selfemployment opportunities will positively affect the process of female empowerment.

The status of women in health can also be visualized from their fertility, maternal mortality and life expectancy ratios. Turning to health, in general women are under a longer life expectancy than men, but this female advantage is somewhat smaller in poor countries. Gross et al. (2019) Healthy life expectancy (HLE) provides an indication of overall health for a population, representing the average equivalent number of years in full health that a newborn could expect to live if they were to pass through life. Qi et al. (2018) life expectancy for women in developing countries is placed on average significantly lower than that of their counterparts in developed countries. Political empowerment of women is one of the key issues of women's empowerment. It refers to the knowledge of political system and ways of access to it, family support for political activities, exercising the rights to vote, activities related to electoral process like voting, campaigning, holding party offices and contesting elections who control how to utilize income (Ager et al., 2018; McKibbin, Shackelford, \& Lopes, 2018).

\section{Methodology}

A cross-country regression analysis will be executed for all the developing countries of the world on the basis of the latest available data. The data will be taken from different sources like Human Development Reports (HDRs) of the UNDP and World Development Indicators (WDI) of the World Bank. In this research the fertility rate of 2014 taking as for dependent variable and other five independent variable like democracy, health, Economically view, education and political situation. Samari (2019) In the second stage of the dependent variable is taking from the fertility rate of 2013 same as independent variables in 2013 and in third stage taking the sum of dependent variable 2014 and 2013 and apply robust test (Phelippeau, Cazalis, \& Koskas, 2019; Wu, Satmary, Peng, \& Hui, 2020) Human development report, UNDP and World Bank 2015 data bases, Polity data scores data sheet, are the sources of data collection for all the indicators and variables of study (Cobo et al., 2020; Sciorio \& Anderson, 2019; Tierney, 2020).

\subsection{Sample Size and Data}

Our sample size constitutes 124 developing countries for which recent data are available. The reason for taking this sample is that developing countries are characterized by common developmental issues and similar developing features. And it will be reasonable / logical to measure the effects of the determinants of women empowerment on the basis of shared characteristics. This is a cross sectional study. Data is taken for the years 2013 and 2014 to measure the process.

\subsection{Methods and Procedures}

However, on the basis of our previous chapter's knowledge the general functional form of our research model is as under:

$$
\mathrm{WE} \text { it }=\mathrm{F} \sqsubset \mathrm{Di}_{\mathrm{t}-1}, \mathrm{Hi}_{\mathrm{t}-1}, \mathrm{Eci}_{\mathrm{t}-1}, \mathrm{Edi}_{\mathrm{t}-1}, \mathrm{Pi} \mathrm{t}_{\mathrm{t}-1}
$$

The above model shows the effect of all the selected independent variables on the dependent variable i.e. women empowerment, where $t$ stand for the 2014, and t-1 represents the year 2013.

In this model, 'WE' stand for women empowerment. This variable is indicated by the fertility rate. D' stands for democracy, H' stands for female health status "Ec' represents Economically view , Ed' stands for female education, 'P' represents the rate of political, it is being used to proxy for the prevalence of democratic culture in a society and participation of women in a country. Moreover ' $\mathrm{F}$ ' is the functional notation and ' $\mathrm{i}$ " represents developing countries.

Econometric form of our basic model will be as under:

$$
\text { (W.E) } \mathrm{i}=\beta_{0}+\beta_{1} \mathrm{Di}+\beta_{2} \mathrm{Hi}+\beta_{3} \mathrm{Ei}+\beta_{4} \mathrm{Edi}+\beta_{5} \mathrm{Pi}+\mathrm{ei}
$$

$\beta_{0}$ is the constant intercept, $\alpha_{1} \alpha_{2} \alpha_{3} \alpha_{4} \alpha_{5}$ is the coefficients of independent variables i.e. female education, control over resources, health status, political participation and democracy respectively and "e" Represents random term or it is residual. "i" indicates sample size i.e. 124 developing countries.

\subsection{Data Analysis Tools}

Our research to analyze the data requires a quantitative approach. The datum needs to be analyzed using multiple regression analysis. This is a statistical technique to examine the relation between one or single dependent and several independent variables. As in multiple regression analysis, independent variables are utilized to predict dependent variables. In this type of statistical analysis, a linear combination of independent variables is the most authentic tool to predict a dependent variable, which is called the regression equation or model of regression. A linear regression equation is usually of the following form:

Women empowerment $=\beta_{\mathrm{o}}+\beta_{1}$ Democracy $_{1}+\beta_{2}$ Health $_{2}+\beta_{3}$ Economically view $_{3}+\beta_{4}$ Education $_{4}+\beta_{5}$ Political view ${ }_{5}+\mathrm{e}$

$\beta_{\mathrm{o}}=$ constant (it is equal to the mean if slope coefficients are zero)

Based on the above equation, the regression equation for our research study can be built as under five individual models. 


\section{Data Analysis}

In data analysis procedure, the results have manipulated and finally conducted by descriptive statistically model. Researcher has modified the critical value of each dependent and independent value by six models under the hypothesis evaluation. Research by quantitative techniques the secondary data has been analyzed by using Multi regression model. This statistically techniques have created the relation individually and have interoperable the female fertility factors by different independent variables. The variables analyzed the relationships between cross dependent variables. In Multi regression, the statistically values have predicted the dependent variables. And, these predicted values have also determined the predicted and explained values ( $\mathrm{Ng} \& \mathrm{Wang}, 2020)$.

There are five models have determined the statistically value of Multi-regression by following

\subsection{Democracy Test}

Democracy test have conducted on fertility rate of 2014 which is computed on bases of 2013 democracy rate, parliamentary seat, tertiary education, life expectancy and female income. The democracy test computed on 2013 individually as following equation.

Fertility 2014 $=$ Constant $+\beta_{1}$ Democracy $+\beta_{2}$ Parliament $+\beta_{3}$ Tertiary Education $+\beta_{4}$ Life Expectancy $+\beta_{5}$ Female income+ e

\subsection{Economically View}

Economic test has conducted on fertility rate of 2014 which is computed on bases of 2013 Democracy, Female income, Gross secondary female education, maternal mortality, and female labor force Participation. The economic test computed on 2013 individually as following equation.

Fertility 2014 $=$ Constant $+\beta_{1}$ Democracy $+\beta_{2}$ Female income $+\beta_{3}$ Gross secondary female education $+\beta_{4}$ Maternal mortality $+\beta_{5}$ Female labor force participation $+\mathrm{e}$

\subsection{Health Test}

Health test have conducted on fertility rate of 2014 which is computed on bases of 2013 democracy rate, parliamentary seat, Gross secondary education, maternal mortality and Female employment. The health test computed on 2013 individually as following equation.

Fertility 2014 $=$ Constant $+\beta_{1}$ Democracy $+\beta_{2}$ Parliament $+\beta_{3}$ Gross secondary education $+\beta_{4}$ Maternal mortality $+\beta_{5}$ Female Employment $+\mathrm{e}$

\subsection{Education Test}

Education test have conducted on fertility rate of 2014 which is computed on bases of 2013 Democracy, female income, female gross primary education, maternal mortality and female per-capita Income. The education test computed on 2013 individually as following equation.

Fertility 2014 $=$ Constant $+\beta_{1}$ Democracy $+\beta_{2}$ Female income $+\beta_{3}$ Female gross primary education $+\beta_{4}$ Maternal mortality $+\beta_{5}$ Female per capita Income $+\mathrm{e}$

\subsection{Political Viere}

Political test have conducted on fertility rate of 2014 which is computed on bases of 2013 Democracy, female income, females mean years of schooling, female per-capita income and female life expectancy. The Political test computed on 2013 individually as following equation.

Fertility 2014 $=$ Constant $+\beta_{1}$ Democracy $+\beta_{2}$ Parliamentary seats $+\beta_{3}$ Females mean years of schooling $+\beta_{4}$ Female per-capita income $+\beta_{5}$ Female life expectancy $+\mathrm{e}$

The women's empowerment is necessary for the whole society. It may be defined as a process, the result of which may come out in such a way that women become able to take control of their lives, improve their skills, become able to solve their problems, and develop their inner qualities of self-reliance and confidence. Women empowerment means that through women aware of their rights and self-confidence women improve and develop their ability to bring a change in her life. Women empowerment is the process which can be defined as treating women like the equal companions with the same rights and duties as men have and increase their spiritual, political impact, social or economic strength (Keats, 2018).

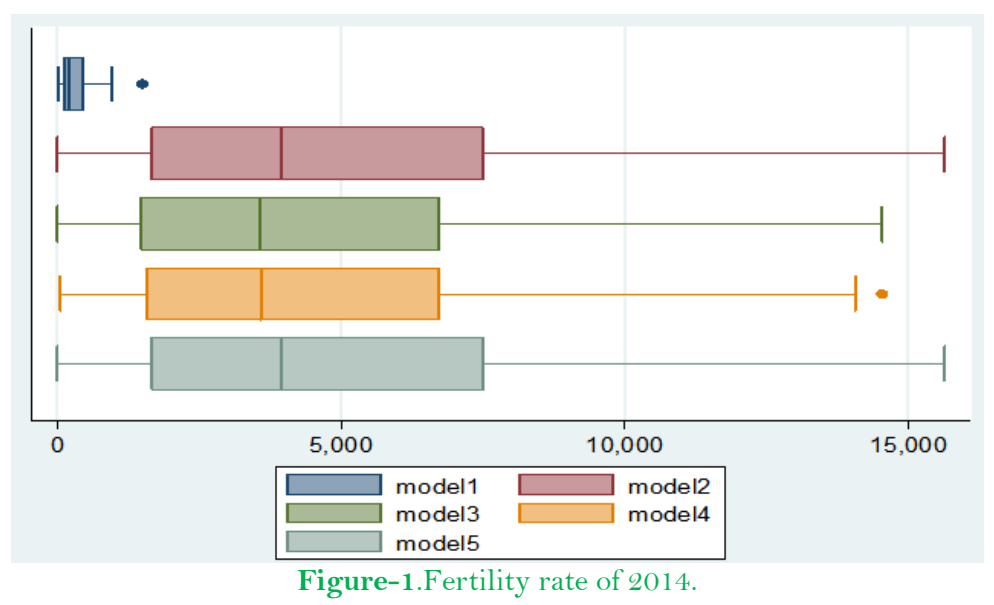

Figure 1 shows different box regarding model 1 to 5, democracy, economically view, health, education and politics respectively. Health and politics have directly impact on the women empowerment as compare to others. Each model has elaborated regarding above equations with fertility 2014 individually. 
Baysal et al. (2018) identified the following dimensions which should be considered while measuring the process of empowerment i.e. legal, political impact, and economic and socio-cultural dimensions. Global health institute survey 2014 also indicates that female empowerment has multiple, interrelated and interdependent dimensions i.e. economic, social, cultural and political impact.

That there are a lot of factors through which the process of women empowerment can be increased i.e. increasing their rights, resources, dignity, choices and opportunities. Gambia found that there exists a strong positive relation between various socio economic and political impact aspects of women participation and the level of women empowerment. They concluded that women always want to improve their lives and wellbeing will increase their participation in all respects of lives and will also increase their confidence (Zhang \& Li, 2017)

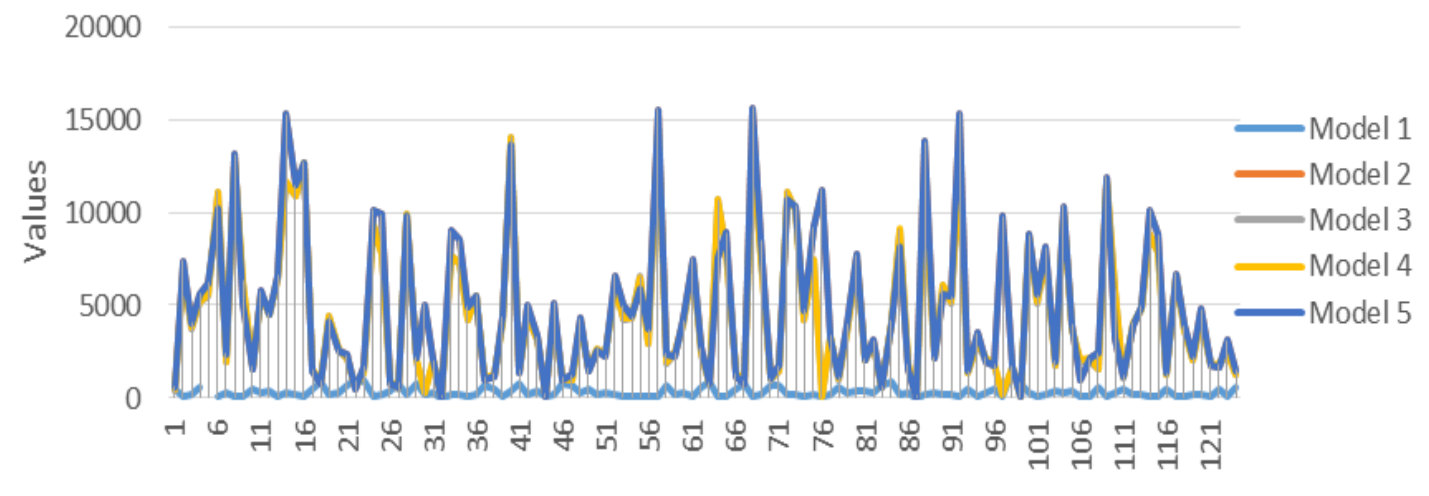

Countries

Figure-2.Models distributed by countries.

Figure 2 shows 124 countries data along with different models. The democracy, economically impact, health, education, and politics respectively indicate different peaks. The politically involvement highly impact on women empowerment in all countries. According to Beach E. observed education, good health and income as necessary for the women empowerment. He concluded that these factors are closely related to the process. He examined the impact of education on the empowerment of women as well as the challenges and changes that could be faced during the process. The various socio economic and cultural variables, which can affect women empowerment, found that there are a number of factors which affect process of women empowerment in a society (Van et al., 2017).

\section{Results}

\subsection{Mean and Standard deviation of Models}

Interpretation: Table 1 is indicated the descriptive statistics; variables models have shown the different value of mean of $\mathrm{N}=124$ the highest mean of political involvement is 4898.234 which is $8.6 \%$ greater from education of female and $6.3 \%$ respectively from democracy rate. The standard deviation value shows the significant relation with each individual variable. The obtained values of these models show the significant result. The means that shows the significant on women empowerment. Therefore, the obtained results show the expressive values of variables in $\mathrm{N}=124$ individually.

\begin{tabular}{|c|c|c|c|c|}
\hline Variable & Mean & Sd & Variance & Sleekness \\
\hline Fertility 2014 & 257.7823 & 246.6212 & 71619.03 & 1.54527 \\
\hline Democracy & 311.0230 & 262.6028 & 68960.21 & 1.462451 \\
\hline Economically view & 321.1452 & 259.9577 & 67578.0 & 1.440435 \\
\hline Health & 4436.229 & 3985.261 & 1.35000 & 0.924417 \\
\hline Education & 4473.826 & 3670.528 & 1.350000 & 0.925115 \\
\hline Political impact & 4898.234 & 3985.261 & 1.590000 & 0.960887 \\
\hline
\end{tabular}

\subsection{Liner Regression Analysis of Models}

The liner regression model of democracy test shows the insignificant effect on the women improvement. The coefficient for democracy is 0.08144. This means that for a 1-unit increase in the democracy, expect an approximately $1 \%$ point increase in the women improvement. This is statistically insignificant; in other words, the coefficients having p-values less than alpha are statistically insignificant. The coefficient for democracy is (.0.744) is not significantly different from 0 using alpha of 0.05 because its p-value is 0.744 , which is greater than 0.05 . The coefficient for democracy (.0255) is statistically have created negative effects on individually, because its p-value is definitely greater than 0.05. The (t-value) 0.33 is less than 2 which is also shows the insignificant effects on the women improvement individually.

The coefficient for economically view is 0.77719 . This means that for a 1-unit increase in the economically view, expect an approximately $1 \%$ point increase in the fertility 2014. This is statistically significant; in other words, the coefficients having p-values less than alpha are statistically significant. The coefficient for economically view is (.002) is significantly different from 0 using alpha of 0.05 because its p-value is 0.002 , which is less than 0.05. The coefficient for economically view is statistically have created positive effects on individually, because its p-value is definitely less than 0.05 .

The sum of SS Model/SS total is equal to 7434168.59, the value of R-Square is 0.8185 and $\mathrm{R}^{2}$ is 0.8107 . The degree of freedom associated with source of variance; the model degrees of freedom corresponds to the number of predictors minus $1(\mathrm{~K}-1)$. The total variance is $\mathrm{N}-1$, there are 1 predictor of independent variable so the $\mathrm{df}$ is (1242 ) is and the Sum of Squares divided by their respective df. For the models 6087816.96 / $5=1211693.39$. For the 
Residual, $1349351.63 / 117=11532.9199$, these are computed so you can compute the $\mathrm{F}$ ratio, dividing the Mean Square Model by the Mean Square Residual to test the significance of the predictors in the model. F and Prob $>$ F - The F-value is the Mean Square Model (1216963.39) divided by the Mean Square Residual (11532.9199), yielding $\mathrm{F}=105.22$ the $\mathrm{p}$-value associated with this $\mathrm{F}$ value is very small (0.0000). The root MSE - Root MSE is the standard deviation of the error term, and is the square root of the mean square residual, which is 107.39. This estimated table shows the relationship between democracy, economically view, health, education, politics and dependent variable women improvement. These estimates shows the amount of increase in fertility scores that would be predicted by a 1 unit increase in the predictor.

\subsection{Regression Analysis of Models}

Table-2. Regression analysis of all models

\begin{tabular}{c|c|c|c|c|c}
\hline Source & Democracy & Economically view & Health & Education & Political impact \\
\hline $\mathrm{t}$-test & 22.36 & 23.51 & -5.17 & -5.16 & -5.58 \\
\hline $\mathrm{P}>|\mathrm{t}|$ & 0.000 & 0.000 & 0.000 & 0.000 & 0.000 \\
\hline Coefficient of Model & 0.8423 & -0.0278 & -0.0284 & -0.0284 & -0.0278 \\
\hline $\mathrm{F}(1,122)$ & 493.00 & 552.84 & 26.71 & 26.630 & 31.090 \\
\hline
\end{tabular}

Table 2 shows the individually effects of each predictor on women empowerment. The ( $t$-value) of individually model is 22.36 in democracy which is greater than 2 , The significant F-Value typically $(\mathrm{p}<.05)$, and the predicator result shows the $\mathrm{F}$ value is.000 it means it less the.05 so it shows the significant effects on fertility 2014 the dependent variable, which is proxy of women empowerment. The coefficient of democracy is 0.84231 with Rsquare 0.8029 with $n=124$ number of individuals. The obtained value of model 2 economic ( $t$-value) of individually model is 23.51 in Economically view which is greater than 2, The significant F-Value typically $(\mathrm{p}<.05)$, and the predicator result shows the $\mathrm{F}$ value is.000 it means it less the.05 so it shows the significant effects on fertility 2014 the dependent variable. The coefficient of economically view is 0.858670 with R-square 0.8192 with $\mathrm{n}=124$ number of individuals.

\subsection{Pearson Correlation of Models}

Table-3. Correlation.

\begin{tabular}{c|c|c|c|c|c|c}
\hline & $\begin{array}{c}\text { Fertility } \\
\mathbf{2 0 1 4}\end{array}$ & Democracy & $\begin{array}{c}\text { Economically } \\
\text { view }\end{array}$ & Health & $\begin{array}{c}\text { Education } \\
\text { Political } \\
\text { impact }\end{array}$ \\
\hline Fertility 2014 & 1.0000 & & & & & \\
\hline Democracy & 0.8961 & 1.0000 & & & & \\
\hline Economically view & 0.9045 & 0.9880 & 1.0000 & & & \\
\hline Health & -0.4232 & -0.4793 & -0.4682 & 1.0000 & & \\
\hline Education & -0.4236 & -0.4784 & -0.4678 & 0.9999 & 1.0000 & \\
\hline Political impact & -0.4500 & -0.5072 & -0.4957 & 0.9198 & 0.9189 & 1.0000 \\
\hline
\end{tabular}

Table-4.Pairwise correlation with 2013 to 2014.

\begin{tabular}{c|c|c|c|c|c|c}
\hline & Fertility 2013-14 & Democracy & $\begin{array}{c}\text { Economically } \\
\text { view }\end{array}$ & Health & $\begin{array}{c}\text { Education } \\
\text { Political } \\
\text { impact }\end{array}$ \\
\hline Fertility 2013-14 & 1.0000 & & & & & \\
\hline Democracy & 0.9383 & 1.0000 & & & & \\
\hline Economically view & 0.9403 & 0.9880 & 1.0000 & & & \\
\hline Health & -0.4511 & -0.4793 & -0.4682 & 1.0000 & & \\
\hline Education & -0.4501 & -0.4784 & -0.4678 & 0.9999 & 1.0000 & \\
\hline Political impact & -0.4841 & -0.5072 & -0.4957 & 0.9198 & 0.9189 & 1.0000 \\
\hline
\end{tabular}

Table-5. Pairwise correlation with 2013.

\begin{tabular}{c|c|c|c|c|c|c}
\hline & Fertility 2013 & Democracy & $\begin{array}{c}\text { Economically } \\
\text { view }\end{array}$ & Health & $\begin{array}{c}\text { Education } \\
\text { Political } \\
\text { impact }\end{array}$ \\
\hline Fertility 2013 & 1.0000 & & & & & \\
\hline Democracy & 0.9426 & 1.0000 & & & & \\
\hline Economically view & 0.9386 & 0.9880 & 1.0000 & & & \\
\hline Health & -0.4602 & -0.4793 & -0.4682 & 1.0000 & & \\
\hline Education & -0.4588 & -0.4784 & -0.4678 & 0.9999 & 1.0000 & \\
\hline Political impact & -0.4977 & -0.5072 & 1.0000 & 0.9198 & 0.9189 & 1.0000 \\
\hline
\end{tabular}

Table-6. AIC and BIC.

\begin{tabular}{c|c|c|c|c}
\hline Sources & AIC & BIC & R & Adjusted R $^{\mathbf{2}}$ \\
\hline Democracy & 1507.439 & 1513.063 & 0.8029 & 0.8013 \\
\hline Economically view & 1508.745 & 1514.386 & 0.8192 & 0.8177 \\
\hline Health & 1696.291 & 1701.93 & 0.1769 & 0.1729 \\
\hline Education & 1696.361 & 1702.002 & 0.1719 & 0.1724 \\
\hline Political impact & 1692.688 & 1698.328 & 0.2031 & 0.1966 \\
\hline
\end{tabular}

\section{Discussion and Finding}

First Hypothesis: The women should have equal opportunities to participate in socio economic and political frameworks. Carlberg, Singer, and Vichinsky (2018) and the female empowerment it is necessary that women 
should be in a position to act freely, and acquire power to exercise their rights and potentials. Thus, women empowerment can be described as a process through which women get an equal and equitable status and position in a society of individual variables.

Researcher obtains statistically significant constant term in different variables, and the women improvement has analyzed with (t-value) is 22.20 in Democracy with $\mathrm{P}>|\mathrm{t}|$ 0.000. 1-unit increase in the democracy, expect an approximately 0.842 percent increase in fertility 2004. A number of researches on women empowerment have concluded that democracy participation of females can increase their knowledge, confidence, skills and empowerment level. An economically empowered woman will come out control over various financial and material resources. Stevenson, Hurt, and Trotter (2017) Therefore, the fertility rate of 2014 has analyzed the value along with R-squared, which determined the significant relations with it.

The obtained values of the collinearity statistics show the stepwise multiple linear regression analysis, that researcher have determined a non-significant intercept but highly significant vehicle theft coefficient for collinearity test, which the researcher can interpret as for every $n=124$ samples individually. The Pearson correlation of $r=0.9880$ with economically view and -0.5072 with politics Table 4 , therefore it creating the negative effects on economically view, health and politics individually. The sample provided sufficient evidence to conclude that there is a significant, nonzero correlation in the population. The test based on $\alpha=.05$ in the critical region of a two tail tests. According to Robust test Table $5 \mathrm{r}=0.9426$, which is $4.9 \%$ greater as compare to fertility in 2014. So, in the same period the obtained value in same year is greater comparatively fertility of 2014. The Robust test shows the highly significant value as compare to 2014 individually. Regarding fertility 2013 and 2014 the $\mathrm{r}=0.938$ which is greater $4.49 \%$ in fertility 2014 and $0.4 \%$ in fertility 2013 . Therefore, the summation of year's fertility shows highly significant value compare to lag years.

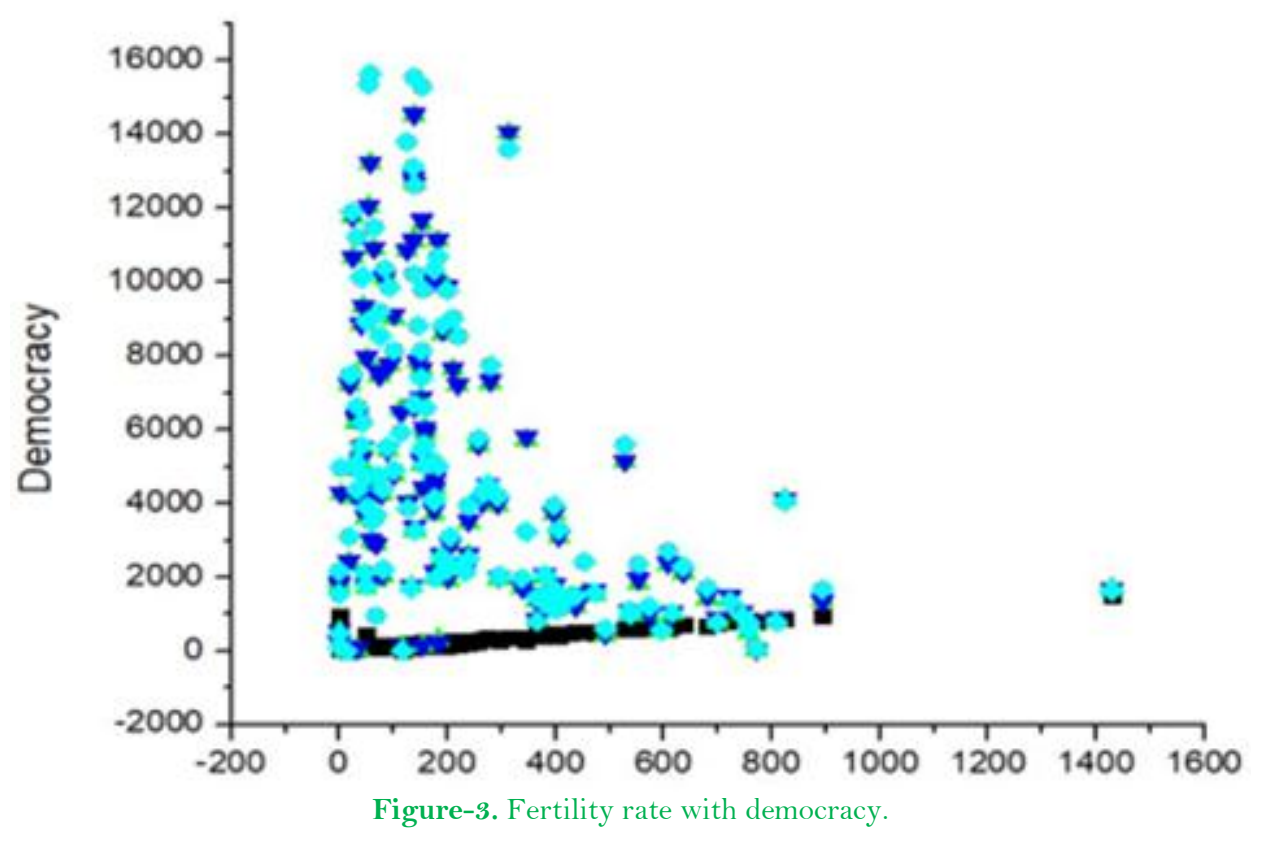

Figure 3 shows the democracy of women empowerment in the fertility rate of 2014 , the model have elaborated fertility rate of 2014 which is computed on bases of 2013 democracy rate, parliamentary seat, tertiary education, life expectancy and female income. The highest rate of democracy is between 0 to 1000 in axes and the democracy of women have increase in period of 0.

Second Hypothesis: The developing countries socio-economic condition can be helpful to promote women status. Economically view approximates an egalitarian system or a system where women have equal rights and opportunities to participate in socio economic and political spheres. Researcher obtains statistically significant constant term in different variables, and the women improvement has analyzed with 0.9045 in economically view and 0.9880 with democracy. The obtained values of the collinearity statistics show the stepwise multiple linear regression analysis, that researcher have determined a non-significant intercept but highly significant vehicle theft coefficient for collinearity test, which the researcher can interpret as for every $n=124$ samples individually. The Pearson correlation of $\mathrm{r}=0.9880$ with democracy and with politics is -0.4957 Table 3, therefore it creating the positive effects on democracy and negative impact on education and politics individually (Altiparmak \& Derya, 2018)

The sample provided sufficient evidence to conclude that there is a significant, nonzero correlation in the population. The test based on $\alpha=.05$ in the critical region of a two tail tests. According to Robust Test Table $5 \mathrm{r}=$ 0.9386 , which is $3.36 \%$ greater as compare to fertility in 2014 . So, in the same period the obtained value in same year is greater comparatively fertility of 2014. The Robust test shows the highly significant value as compare to 2014 individually. Regarding fertility 2013 and 2014 the $\mathrm{r}=0.9403$ which is greater $3.60 \%$ in fertility 2014 and $.018 \%$ in fertility 2013. Therefore, the summation of year's fertility shows highly significant value compare to lag years. 


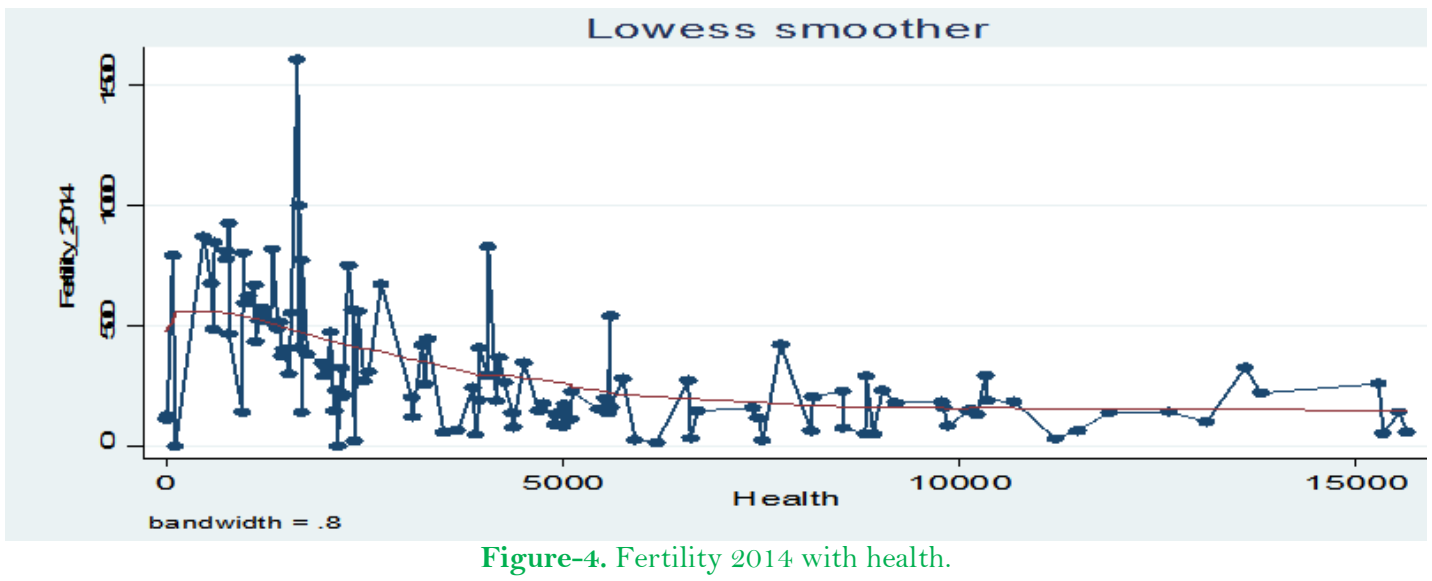

Figure 4, shows the Lowess smoother of fertility 2014 and health. Where the expected bandwidth of 0.8 is used, so it shows $80 \%$ of data are used in smoothing each point. And smaller bandwidth follows the original data more closely in this model.

Third Hypothesis: Third Hypothesis: The women empowerment means that through women aware of their rights and self-confidence women improve and develop their ability to bring a change in her life. Park et al. (2017) Women empowerment is a work which can be defined as treating women like the equal companions with the same rights and duties as men have and increase their spiritual, political, social, or economic strength. Empowering women enhance their ability to influence changes and to create a better society.

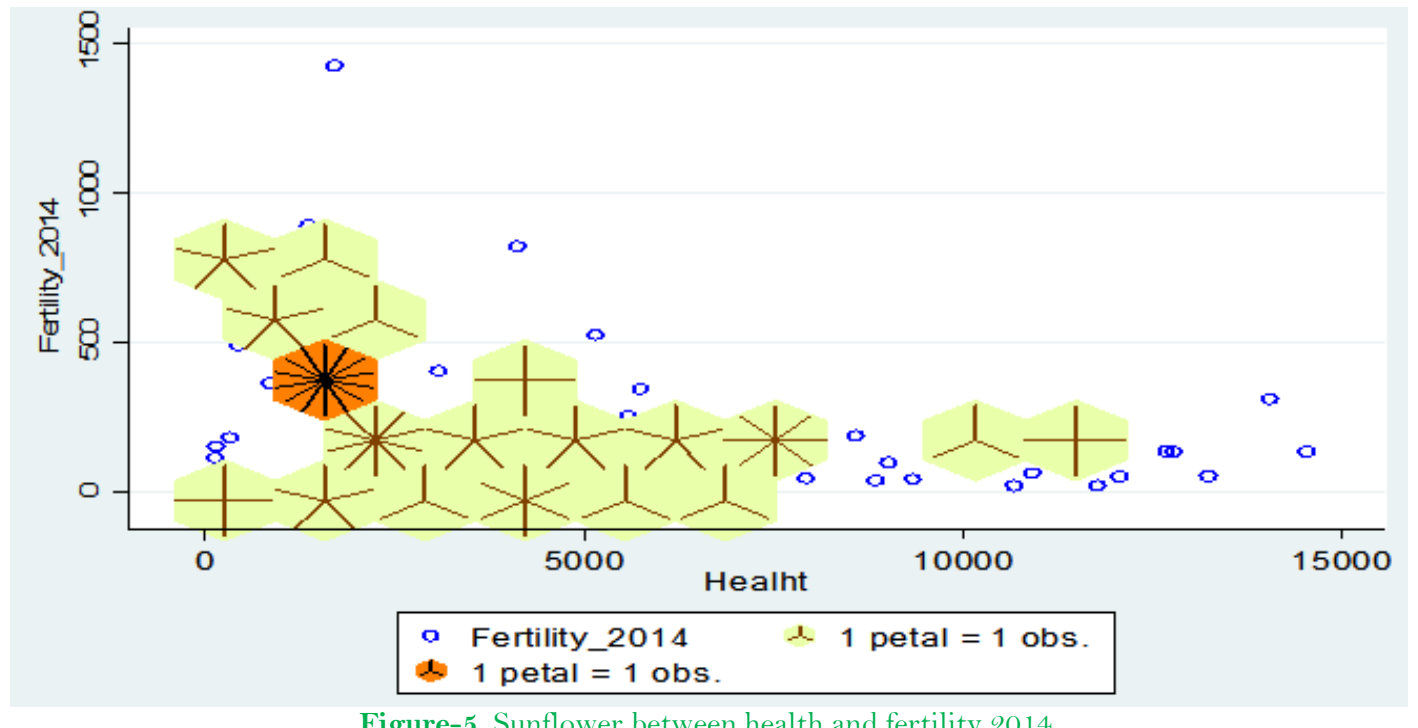

Figure-5. Sunflower between health and fertility 2014.

Figure 5 shows the minimum observation in sunflower is 3 in light and 13 in dark view. The bin height of fertility 2014 and health is chosen to make bin regular hexagons with maximum of 1 dark Patel form 14 maximum observation in bin, the blue circles shows the individual observation of model, brown petal on green background shows the light sunflowers and black petal on orange background shows dark sunflowers in 124 number of observations.

Researcher obtains statistically significant constant term in different variables, and the women improvement has analyzed with Democracy, Parliament seat, Gross Enrollment in Primary Education, Secondary Education, Maternal and Female Labor.

Researcher obtains statistically significant constant term in different variables, and the women improvement has analyzed with -0.4232 in health view and -0.4682 with economically and -0.4793 with democracy Table 3, Therefore, it creating the negative effects on democracy and economically view individually and shows the weak relationship among them.

The sample provided sufficient evidence to conclude that there is a significant, nonzero correlation in the population. The test based on $\alpha=.05$ in the critical region of a two tail tests. According to Robust test Table $5 \mathrm{r}=-$ 0.4602 , which is $8.03 \%$ greater as compare to fertility in 2014 . So, in the same period the obtained value in same year is greater comparatively fertility of 2014. The Robust test shows the highly significant value as compare to 2014 individually. Regarding fertility 2013 and 2014 the $\mathrm{r}=-0.4511$ which is greater $6.18 \%$ in fertility 2014 and 2.02\% in fertility 2013. Therefore, the summation of year's fertility shows highly significant value compare to lag years. 


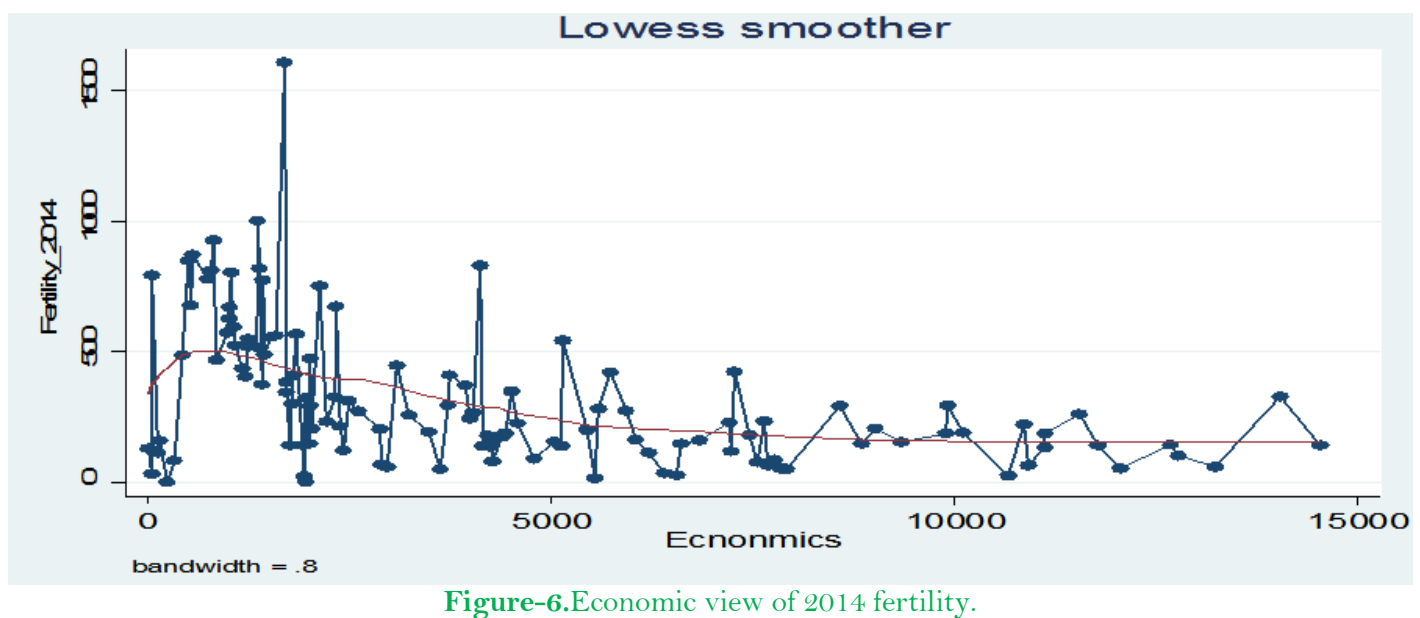

Figure 6, shows the Lowess smoother of fertility 2014 and economically view. Where the expected bandwidth of 0.8 is used, so it shows $80 \%$ of data are used in smoothing each point. And smaller bandwidth follow the original data more closely in this model.

Fourth Hypothesis: The "empowerment" is a process of development by which the disempowered individuals and groups become able to control and manage their lives. Other researchers highlighted that the economic elements of empowerment refer primarily to the capability of women's earnings for a living. Women are important for growth and development but in most of the developing societies women are deprived of their basic rights to get education, health and inheritance.

Researcher obtains statistically significant constant term in different variables, and the women improvement has analyzed with -0.4226 in education and -0.4784 with democracy, -0.4678 with economically view and .9999 with health Table 3, The obtained values of the collinearity statistics show the stepwise multiple linear regression analysis, that researcher have determined a non-significant intercept but highly significant vehicle theft coefficient for collinearity test, which the researcher can interpret as for every $n=124$ samples individually. Therefore, it creating the negative effects on democracy and economically view but created positive and strongly correlated with health individually.

The sample provided sufficient evidence to conclude that there is a significant, nonzero correlation in the population. The test based on $\alpha=.05$ in the critical region of a two tail tests. According to Robust Test Table 5 , $\mathrm{r}=$ -4226 , which is $7.89 \%$ greater as compare to fertility in 2014 . So, in the same period the obtained value in same year is greater comparatively fertility of 2014. The Robust test shows the highly significant value as compare to 2014 individually. Regarding fertility 2013 and 2014 the $\mathrm{r}=-0.4501$ which is greater $6.10 \%$ in fertility 2014 and $1.93 \%$ in fertility 2013. Therefore, the summation of year's fertility shows highly significant value compare to lag years.

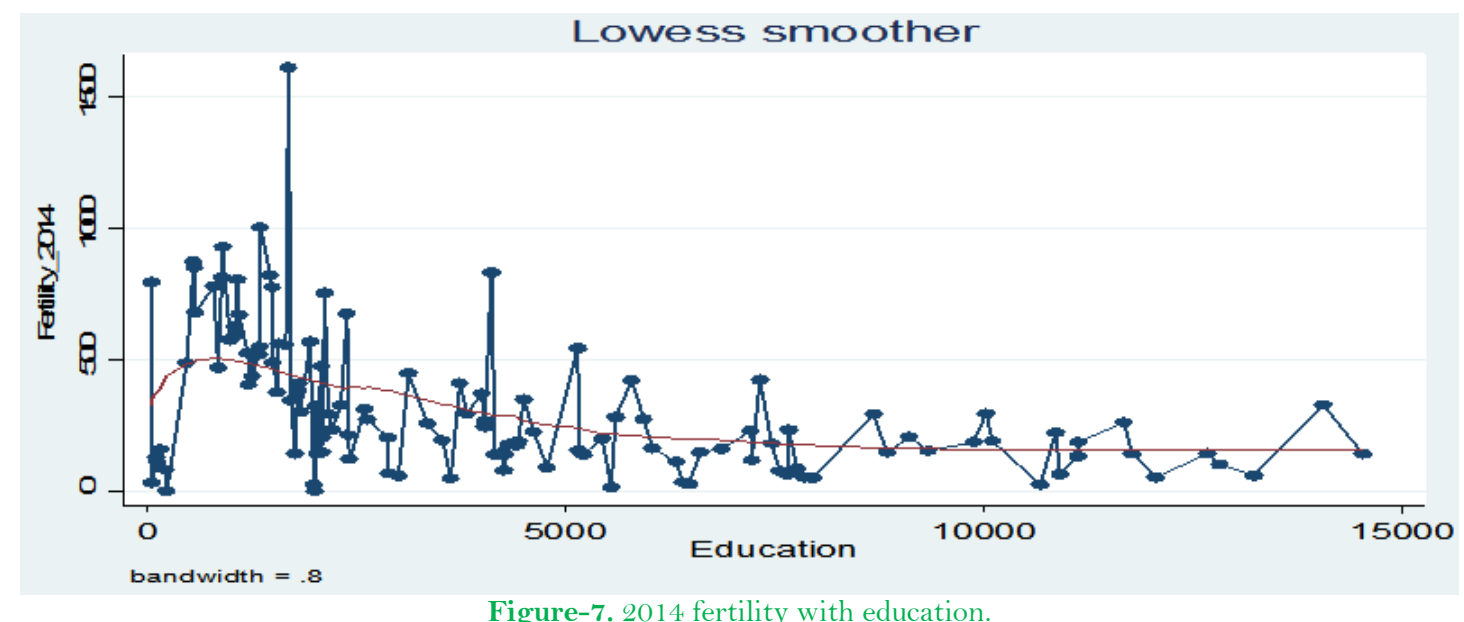

Figure 7, shows the Lowess smoother of fertility 2014 and economically view. Where the expected bandwidth of 0.8 is used, so it shows $80 \%$ of data are used in smoothing each point. And smaller bandwidth follow the original data more closely in this model.

Fifth Hypothesis Researcher obtain statistically significant constant term in different variables, and the women improvement has analyzed with Democracy, Parliament seat, Mean years of Schooling Females, Female Income Per Capita, and Females life expectancy 2013.

Researcher obtains statistically significant constant term in different variables, and the women improvement has analyzed with -0.4500 in politics and -0.5072 with democracy, -0.4957 with economically view, 0.9198 with health and 0.9189 with education Table 3, The obtained values of the collinearity statistics show the stepwise multiple linear regression analysis, that researcher have determined a non-significant intercept but highly significant vehicle theft coefficient for collinearity test, which the researcher can interpret as for every $n=124$ samples individually. Therefore, it creating the negative effects on democracy and economically view but created positive and strongly correlated with health and education individually. 


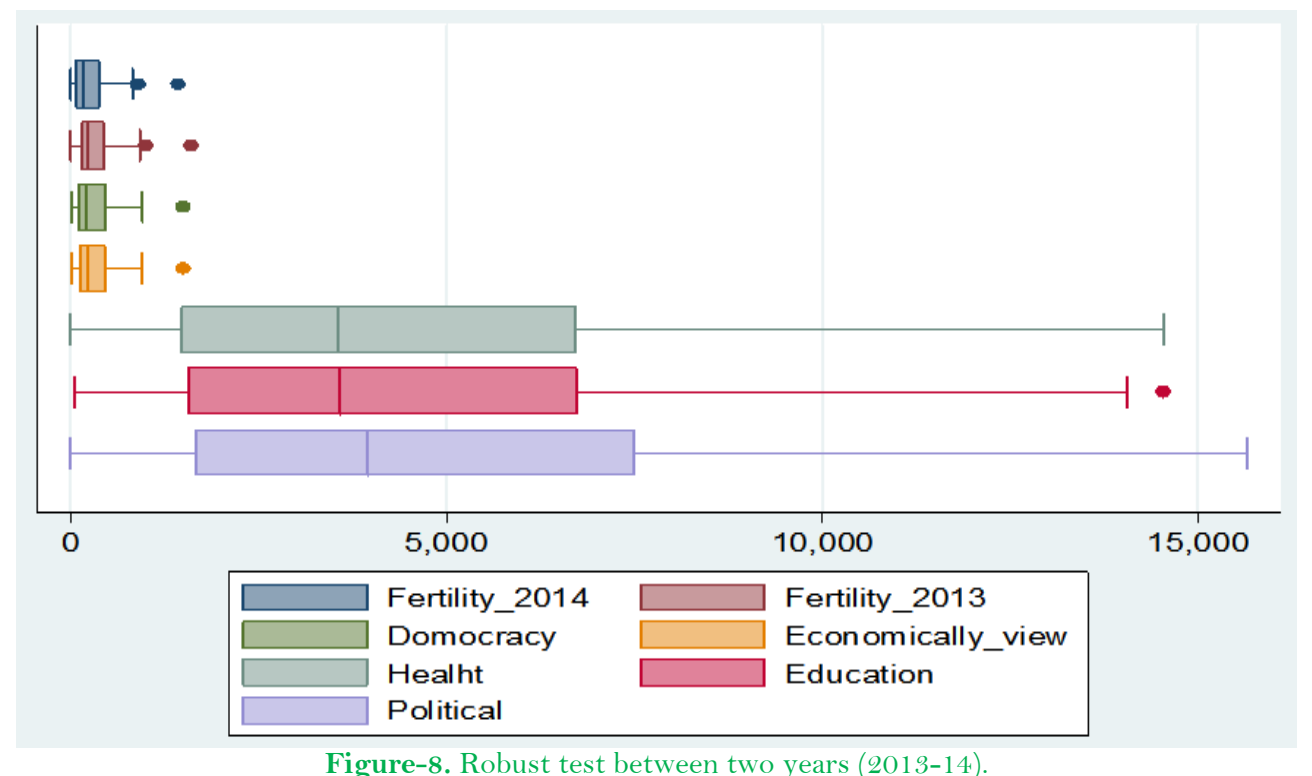

Figure 8, shows the box plot of dependent and independent variables. Where the both years of fertility have taken along with predictors of models. The highest box value is political impact and lowest value is fertility 2013 in lag year. The sample provided sufficient evidence to conclude that there is a significant, nonzero correlation in the population. The test based on $\alpha=.05$ in the critical region of a two tail tests. According to Robust test Table $5, \mathrm{r}=-$ .4500 , which is $9.58 \%$ greater as compare to fertility in 2014 . So, in the same period the obtained value in same year is greater comparatively fertility of 2014. The Robust test shows the highly significant value as compare to 2014 individually. Regarding fertility 2013 and 2014 the $r=-0.4841$ which is greater $7.04 \%$ in fertility 2014 and $5.22 \%$ in fertility 2013. Therefore, the summation of year's fertility shows highly significant value compare to lag years.

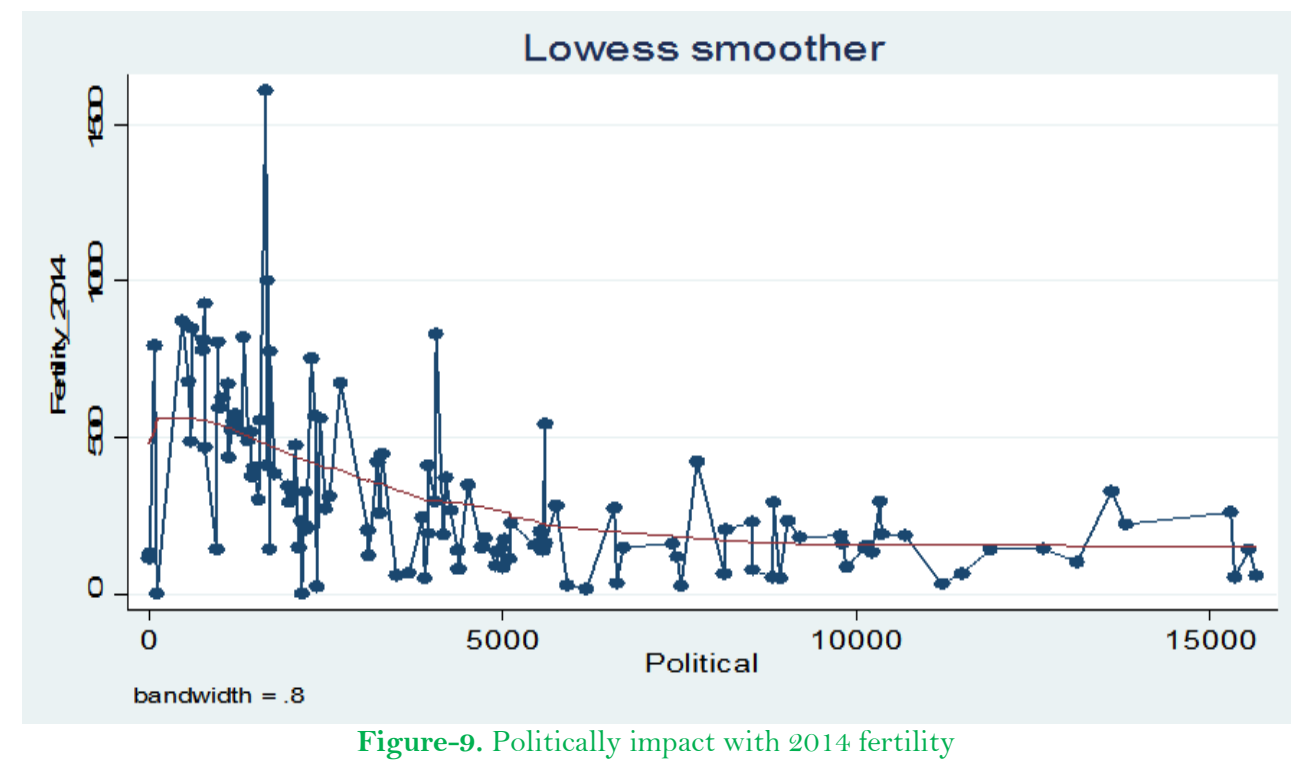

Figure 9, shows the Lowess smoother of fertility 2014 and politically view. Where the expected bandwidth of 0.8 is used, so it shows $80 \%$ of data are used in smoothing each point. And smaller bandwidth follow the original data more closely in this model.

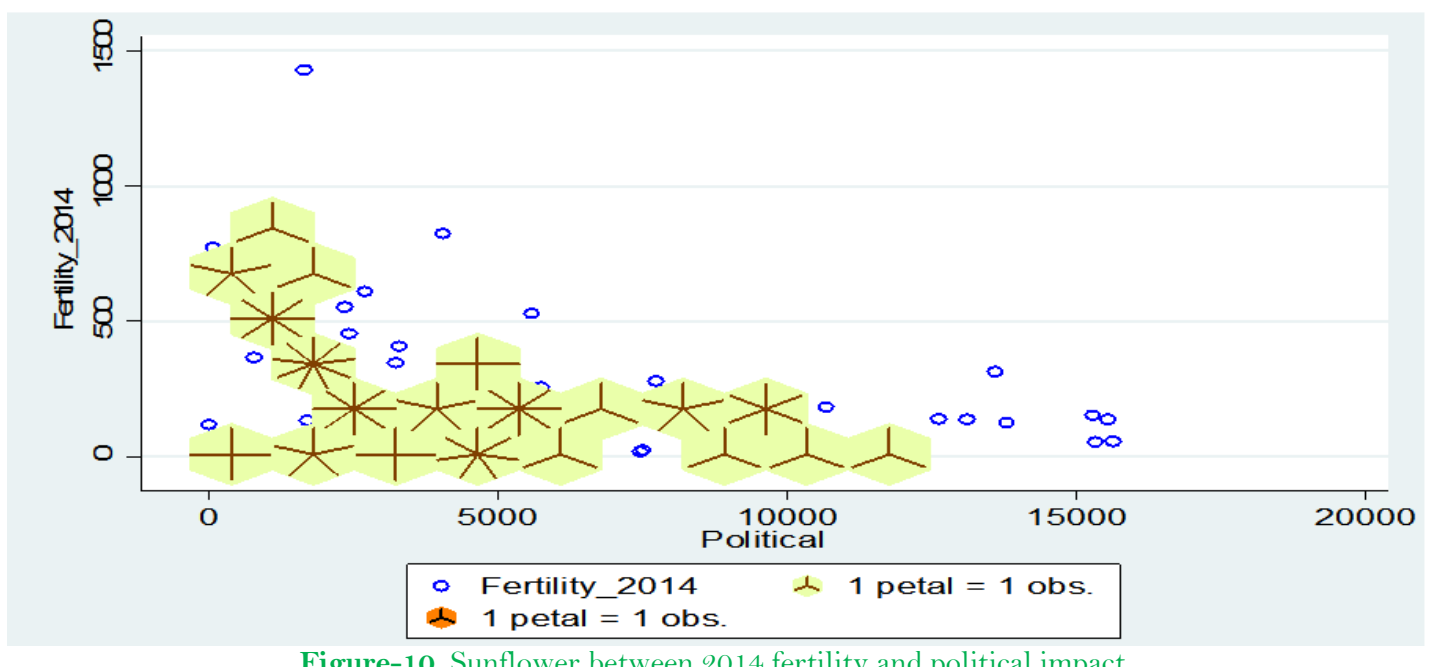

Figure 10 shows the minimum observation in sunflower is 3 in light and 13 in dark view. The bin height of fertility 2014 and political impact is chosen to make bin regular hexagons with maximum of 1 dark Patel form 14 maximum observation in bin, the blue circles shows the individual observation of model, brown petal on green background shows the light sunflowers and black petal on orange background shows dark sunflowers in 124 
number of observations. Table 6 is indicated the Akaike Information Criterion (AIC) is a way of selecting a model from a set of models with different style. The chosen model is the one that minimizes the Kullback-Leibler distance between the model and the truth in different expects. 1507.439 is the value of AIC, as compare to the Bayesian information criterion (BIC) to compare models. The random distribution of variables. In this model BIC value is greater than as compare to AIC. Therefore, this model shows the high random distribution as compare to other individuals. The economically view of women empowerment shows 1508.745 is the value of AIC, in this model BIC value is greater than as compare to AIC. Therefore, this model shows the high random distribution as compare to other individuals. Therefore, this model shows the high random distribution as compare to other individuals. The political impact involvement of women empowerment shows 1692.688 is the value of AIC, as compare to the Bayesian information criterion (BIC) to compare models. The random distribution of variables. In this model BIC value is greater than as compare to AIC. Therefore, this model shows the high random distribution as compare to other individuals. In case of fertility 2014 and economically view of r-square is 0.8192 and 0.2197 with p-value of 0.000 so it shows the view of economic effect on 1 percent 0.8579 but health have directly affected on economically view individually with -0.03310 coefficient value. In other case if fertility 2014 have taking relationship with health r-square shows 0.1796 and 0.998 , it effect on 1 percent of -0.0283665 coefficient value of health. And also, the health education effect on health with 1.002541 coefficient value. In last case the fertility 2014 with education so the r-square is 0.1746 and 0.8445 . The 1 percent change effect on education with -0.0329 the coefficient of education and political impact also effect on education with 0.8463 in endogenous variable of fertility 2014 and education.

\section{Recommendation and Conclusion}

Because of analysis and discussion some findings emerged on the surface which are as follows; About the findings of the analysis the following recommendations are proposed to remove the obstacles and to promote the process of women empowerment;

1. The role and contribution of women through improving and promoting life skills and educational opportunities for them.

2. Also, to strengthen opportunities for post-primary education for girls to ensure their primary education

3. To reduce gender gaps there should be increased opportunities for secondary and tertiary education for girls.

4. There is a strong need to strengthen labor policies affecting women. And expand women's access to credit and economic opportunities.

5. There is a requirement to expand reproductive health programs and family support policies. And strengthen nutrition, disease prevention, and maternal health programs.

6. To ensure women political participation there should be an increase women's share of seats in national parliaments and local governments. And discriminatory laws and gender blind policies should be discouraged.

7. Ensuring female property and inheritance rights and a non-patriarchal culture would help to empower women both economically and socially and rectify a fundamental injustice of gender inequality.

8. Supporting them in information. Knowledge, developing contact, presenting issues, and advocacy skills etc. will also be a very helpful and effective strategy which will ensure their path of empowerment.

9. Initiating and promoting programs for reducing gender gaps necessary for women development.

The study was performed on determining and highlighting the main socio cultural economic and political factors of women empowerment and analyzing the impact of female literacy, economic and political participation, female health services and a non-patriarchal culture in promoting the process. It is concluded that cultural values and patriarchy are responsible for women disempowerment in most of the countries of the third world. Moreover, it has restricted the path of women to get education and access, better health and career opportunities. Lack of education and low literacy is the main deterrents towards women economic disempowerment. And therefore, women of third world countries continue to be lagging behind in every respect of life and participate in politics. Women of underdeveloped countries contain a number of socio economic and political issues which have hindered their path of empowerment. Among all these fertilities is considered to be an important factor which can determine their socio economic and political position and status in various countries. Fertility is also available to be an effective measure of women empowerment. It is found that lower fertility rates and reduce the number of pregnancies in females depict, better health and use of more contraceptives by women. Low fertility also explains that women are controlled by their reproductive decisions in a family.

In the light of above literature, it is concluded that the process of women empowerment is the result of diverse socio cultural economic and political factors. The above literature has also highlighted numerous such factors and variables which are responsible for women disempowerment in developing countries. These factors include, lack and limited access to education, lack of confidence and freedom, lack of control over resources, imbalanced sex ratio, poor health, high fertility and maternal mortality rates, low life expectancy, non-availability of health services, lack of leadership and decision making opportunities and patriarchal culture etc. It is evident from the above literature that though women are facing various obstacles towards their empowerment, but the level of empowerment is also increasing. It is evident from the above literature that the phenomenon of low fertility rates across many of the countries of the world is being helpful in describing the process of women empowerment. The need is that women participation in all respects of lives should be increased which is also crucial for the overall development. Reducing gender gaps and increasing equal socio economic opportunities, will ensure welfare and empowerment.

\section{References}

Ager, B., Jansen, J., Porter, D., Phillips, K., Glassey, R., Rankin, N., \& Skandarajah, A. (2018). Development and pilot testing of a decision Aid (DA) for women with early-stage breast cancer considering contralateral prophylactic mastectomy. The Breast, 40, 156164.Available at: https://doi.org/10.1016/j.breast.2018.05.009. 
Altiparmak, S., \& Derya, Y. A. (2018). The effects of fertility-supporting health training on healthy lifestyle behaviors and infertility selfefficacy in infertile women: A quasi-experimental study. European Journal of Integrative Medicine, 20, 146-153.Available at: https://doi.org/10.1016/j.eujim.2018.05.005.

Baysal, Ö., Hamilton, J. A., Hamilton, C. J., Braat, D. D., Beerendonk, C. C., \& Nelen, W. L. (2018). Clinical practice guidelines for fertility preservation in young women undergoing gonadotoxic treatment: an overview and critical appraisal of methodological quality and content. Reproductive Biomedicine Online, 37(1), 60-70.Available at: https://doi.org/10.1016/j.rbmo.2018.03.022.

Carlberg, K. T., Singer, S. T., \& Vichinsky, E. P. (2018). Fertility and pregnancy in women with transfusion-dependent thalassemia. Hematology/Oncology Clinics, 32(2), 297-315.Available at: https://doi.org/10.1016/j.hoc.2017.1 1.004.

Cobo, A., Giles, J., Paolelli, S., Pellicer, A., Remohí, J., \& García-Velasco, J. A. (2020). Oocyte vitrification for fertility preservation in women with endometriosis: an observational study. Fertility and Sterility, 113(4), 836-844.

Fisch, S. C., Nikou, A. F., Wright, E. A., Phan, J. D., Leung, K. L., Grogan, T. R., \& Dumesic, D. A. (2018). Precocious subcutaneous abdominal stem cell development to adipocytes in normal-weight women with polycystic ovary syndrome. Fertility and Sterility, $110(7), 1367-1376$. Available at: https://doi.org/10.1016/j.fertnstert.2018.08.042.

Goldstein, K. M., Duan-Porter, W., Alkon, A., Olsen, M. K., Voils, C. I., \& Hastings, S. N. (2019). Enrollment and retention of men and women in health services research and development trials. Women's Health Issues, 29, S121-S130.Available at: https://doi.org/10.1016/j.whi.2019.03.004.

Gross, J. P., Whelan, T. J., Parulekar, W. R., Chen, B. E., Rademaker, A. W., Helenowski, I. B., \& Strauss, J. B. (2019). Development and validation of a nomogram to predict lymphedema after axillary surgery and radiation therapy in women with breast cancer from the NCIC CTG MA. 20 randomized trial. International Journal of Radiation Oncology Biology Physics, 105(1), 165-173.Available at: https://doi.org/10.1016/j.ijrobp.2019.05.002.

Jahromi, B. N., Zolghadri, J., Rahmani, E., Alipour, S., Anvar, Z., Zarei, A., \& Keramati, P. (2019). Effect of low-dose aspirin on the development of ovarian hyperstimulation syndrome and outcomes of assisted reproductive techniques in the women with PCOS, a randomized double-blinded clinical trial. Taiwanese Journal of Obstetrics and Gynecology, 58(2), 255-260.Available at: https://doi.org/10.1016/j.tjog.2019.01.016.

Keats, A. (2018). Women's schooling, fertility, and child health outcomes: Evidence from Uganda's free primary education program. Journal of Development Economics, 135(C), 142-159.Available at: https://doi.org/10.1016/j.jdeveco.2018.07.002.

Kim, A. (2018). Gender and labor ethics in aesthetic labor: Female students of specialized vocational home economics high schools in Korea. Asian Journal of Women's Studies, 24(3), 342-367.Available at: https://doi.org/10.1080/12259276.2018.1499458.

Kumar, S. P. (2020). Lakshmi the rebel: Culture, economy and women's agency. Asian Journal of Women's Studies, 26(1), $28-131$.

Liu, Y. Q., Yu, Y., Bai, J. B., \& Chen, X. L. (2020). Development and psychometric properties of the maternal health needs scale in Chinese maternal women. Midwifery, 81, 102588.Available at: https://doi.org/10.1016/j.midw.2019.102588.

Malapit, H., Quisumbing, A., Meinzen-Dick, R., Seymour, G., Martinez, E. M., Heckert, J., \& Yount, K. M. (2019). Development of the project-level women's empowerment in agriculture Index (pro-WEAI). World Development, 122, 675-692.Available at: https://doi.org/10.1016/j.worlddev.2019.06.018.

Matro, R., Martin, C. F., Wolf, D., Shah, S. A., \& Mahadevan, U. (2018). Exposure concentrations of infants breastfed by women receiving biologic therapies for inflammatory bowel diseases and effects of breastfeeding on infections and development. Gastroenterology, 155(3), 696-704.Available at: https://doi.org/10.1053/j.gastro.2018.05.040.

McKibbin, W. F., Shackelford, T. K., \& Lopes, G. S. (2018). Development and initial psychometric validation of the women's partner-directed Insults scale. Personality and Individual Differences, 135, 51-55.Available at: https://doi.org/10.1016/j.paid.2018.06.050.

Montanari, B., \& Bergh, S. I. (2019). Why women's traditional knowledge matters in the production processes of natural product development: The case of the green Morocco plan. Women's Studies International Forum, 77, 102275.Available at: https://doi.org/10.1016/j.wsif.2019.102275.

Ng, W. L., \& Wang, Y.-C. (2020). Waiting as a signal: Why women are delaying fertility? Economic Modelling, 87, 471-479.Available at: https://doi.org/10.1016/j.econmod.2019.12.010.

Park, J.-Y., Seong, S. J., Kim, T.-J., Kim, J. W., Bae, D.-S., \& Nam, J.-H. (2017). Significance of body weight change during fertility-sparing progestin therapy in young women with early endometrial cancer. Gynecologic Oncology, 146(1), 39-43.Available at: https://doi.org/10.1016/j.ygyno.2017.05.002.

Phelippeau, J., Cazalis, C. G., \& Koskas, M. (2019). Ovarian protection and fertility preservation in women with cancer: A French national registry analysis between 2005 and 2014. Journal of Gynecology Obstetrics and Human Reproduction, 48(9), 705-710.Available at: https://doi.org/10.1016/j.jogoh.2019.07.005.

Qi, Y., Wang, W., Zhang, K., An, S., Wang, S., Zheng, J., \& Tang, Y.-D. (2018). Development and validation of women acute myocardial infarction in-hospital mortality score (WAMI Score). International Journal of Cardiology, 259, 31-39.Available at: https://doi.org/10.1016/j.ijcard.2017.12.010.

Riahi, M., Mohammadi, A., Rohani, H., \& Bidkhori, M. (2018). Dataset on the prevalence of tobacco smoking in men and women of selected countries whit difference human development. Data in Brief, 18, 506-511.Available at: https://doi.org/10.1016/j.dib.2018.03.043.

Samari, G. (2019). Education and fertility in Egypt: Mediation by women's empowerment. SSM-Population Health, 9, 100488.Available at: https://doi.org/10.1016/j.ssmph.2019.100488.

Sciorio, R., \& Anderson, R. A. (2019). Fertility preservation and preimplantation genetic assessment for women with breast cancer. Cryobiology, 92, 1-8.Available at: https://doi.org/10.1016/j.cryobiol.2019.12.001.

Stevenson, E. L., Hurt, M. J., \& Trotter, K. J. (2017). Oocyte cryopreservation for fertility preservation in healthy women. Nursing for Women's Health, 21(5), 384-393.Available at: https://doi.org/10.1007/978-4-431-55963-4_1.

Sweeney, A. M., Wilson, D. K., \& Brown, A. (2019). A qualitative study to examine how differences in motivation can inform the development of targeted physical activity interventions for African American women. Evaluation and Program Planning, 77, 101718.Available at: https://doi.org/10.1016/j.evalprogplan.2019.101718.

Teitelman, A. M., Kim, S. K., Waas, R., DeSenna, A., \& Duncan, R. (2018). Development of the Now IKnow mobile application to promote completion of HPV vaccine series among young adult women. Journal of Obstetric, Gynecologic E Neonatal Nursing, 47(6), 844852.Available at: https://doi.org/10.1016/j.jogn.2018.06.001.

Tierney, K. (2020). Is there evidence of weathering among women seeking fertility treatments?: Evidence and insights. Social Science Eீ Medicine, 247, 112816.Available at: https://doi.org/10.1016/j.socscimed.2020.112816.

Van, E. B., Berry, G. T., Cassiman, D., Connolly, G., Forga, M., Gautschi, M., \& Knerr, I. (2017). Fertility in adult women with classic galactosemia and primary ovarian insufficiency. Fertility and Sterility, 108(1), 168-174.Available at: https://doi.org/10.1016/j.fertnstert.2017.05.013.

Vermeulen, J., Peersman, W., Quadvlieg, L., Fobelets, M., De Clercq, G., Swinnen, E., \& Beeckman, K. (2018). Development and validation of the Midwife profiling questionnaire assessing women's preferred perinatal care professional and knowledge of midwives' legal competences. Sexual \& Reproductive Healthcare, 16, 23-32.Available at: https://doi.org/10.1016/j.srhc.2018.01.003.

Wu, X.-Q., Satmary, W., Peng, J., \& Hui, K.-k. (2020). Women's preconception health patterns in traditional Chinese medicine as a predictor of fertility outcomes. Journal of Integrative Medicine, 18(3), 222-228.Available at: https://doi.org/10.1016/j.joim.2020.01.006.

Zhang, C., \& Li, T. (2017). Culture, fertility and the socioeconomic status of women. China Economic Review, 45, 279-288.Available at: https://doi.org/10.1016/j.chieco.2016.07.012. 